\title{
AMBIENTE DE ENRAIZAMENTO E SUBSTRATOS NA MINIESTAQUIA DE ERVA-
} MATE

\section{ENVIRONMENT OF ROOTING AND SUBSTRATUM IN THE MINICUTTING OF ERVA-MATE}

\author{
Gilvano Ebling BRONDANI ${ }^{2}$ \\ Ivar WENDLING ${ }^{3}$ \\ Delmar SANTIN ${ }^{4}$ \\ Eliziane Luiza BENEDETTI ${ }^{5}$ \\ Luís Fernando ROVEDA ${ }^{6}$ \\ Alessandro Góis ORRUTÉA ${ }^{7}$
}

\begin{abstract}
RESUMO
Devido à falta de um método que possibilite a propagação vegetativa da erva-mate de forma eficiente, foi conduzido na Embrapa Florestas, um estudo com objetivo de avaliar o efeito do ambiente de enraizamento e composições de substrato na sobrevivência, enraizamento e crescimento de miniestacas de erva-mate. As brotações foram coletadas de minicepas produzidas via semente e manejadas em sistema semi-hidropônico. O experimento foi conduzido no delineamento blocos ao acaso no arranjo bifatorial, sendo os níveis constituídos de seis diferentes composições de substratos: S1 - substrato para enraizamento a base de casca de Pinus, S2 - substrato para enraizamento a base de casca de Pinus e vermiculita, S3 - casca de arroz carbonizada + vermiculita fina + substrato para enraizamento a base de casca de Pinus e vermiculita $(1: 1: 1 \mathrm{v} / \mathrm{v})$, S4 - casca de arroz carbonizada + substrato para enraizamento a base de casca de Pinus e vermiculita (1:1 v/v), S5 - casca de arroz carbonizada + vermiculita fina $(1: 1 \mathrm{v} / \mathrm{v})$ e $\mathrm{S} 6$ - fibra de coco e, dois ambientes de enraizamento: casa de vegetação automatizada e casa de vegetação simples. Independente das variáveis analisadas, a casa de vegetação com controle de umidade e temperatura foi superior a casa de vegetação sem controle. $O$ uso do substrato casca de arroz carbonizada + substrato para enraizamento a base de casca de Pinus e vermiculita $(1: 1 \mathrm{v} / \mathrm{v})$ é aconselhado nos dois ambientes para o enraizamento de miniestacas juvenis de erva-mate.
\end{abstract}

Palavras-chave: Ilex paraguariensis; propagação vegetativa; clonagem; sistema semi-hidropônico.

\begin{abstract}
The inexistence of one efficient method of vegetative propagation for Ilex paraguariensis difficult the silvicultural advances to this species. The experiment was conducted in Embrapa Florestas aiming to evaluate the initial environment and substratum compositions effects in the survival, rooting and development of $l$. paraguariensis minicuttings. Shoots were collected of ministumps produced by seeds and cultivated in minigarden of semi-hydroponic system. The work was conducted in blocks with bifactorial arrangement. The substratum compositions were: S1 - substratum to rooting with Pinus rind, S2 - substratum to rooting with Pinus rind and vermiculite, S3 - carbonized rice rind + fine vermiculite + substratum to rooting with Pinus rind and vermiculite $(1: 1: 1 \mathrm{v} / \mathrm{v}), \mathrm{S} 4$ - carbonized rice rind + substratum to rooting with Pinus rind and vermiculite $(1: 1 \mathrm{v} / \mathrm{v})$, S5 - carbonized rice rind + fine vermiculite $(1: 1 \mathrm{v} / \mathrm{v})$ and $S 6$ - coconut fiber. The rooting environments were: automatized and simple greenhouses. The results indicated that the greenhouse with controlled humidity and temperature was better in relation at environment without control, independent of the analyzed variable. The substratum mixture with carbonized rice rind + substratum to rooting with Pinus rind and vermiculite $(1: 1 \mathrm{v} / \mathrm{v})$ can be indicated for use in the two rooting environments to $I$. paraguariensis juvenile minicuttings.

Key-words: Ilex paraguariensis; vegetative propagation; cloning; semi-hydroponic system.

\footnotetext{
${ }^{1}$ Trabalho desenvolvido na Embrapa - Florestas, Colombo, Paraná.

2 Engenheiro Florestal, Mestrando do Programa de Pós-Graduação em Engenharia Florestal, Universidade Federal do Paraná, UFPR, CEP 80210-170, Curitiba (PR), Bolsista do Cnpq, Email: gebrondani@yahoo.com.br.

${ }^{3}$ Engenheiro Florestal, Doutor em Silvicultura, Pesquisador da Embrapa Florestas - CNPF. Estrada da Ribeira Km 111, CEP 83411-000, Colombo (PR). Email: ivar@cnpf.embrapa.br. Autor para correspondência.

${ }^{4}$ Engenheiro Florestal, Mestrando do Programa de Pós-Graduação em Ciência do Solo, Universidade Federal do Paraná, UFPR, CEP 80035050, Curitiba (PR), Bolsista CAPES.

${ }^{5}$ Engenheira Agrônoma, Mestranda do Programa de Pós-Graduação em Ciência do Solo, Universidade Federal do Paraná, UFPR, CEP 80035050, Curitiba (PR), Bolsista CAPES.

${ }^{6}$ Engenheiro Agrônomo, Mestrando do Programa de Pós-Graduação em Ciência do Solo, Universidade Federal do Paraná, UFPR, CEP 80035050, Curitiba (PR).

${ }^{7}$ Engenheiro Agrônomo, Mestrando do Programa de Pós-Graduação em Ciência do Solo, Universidade Federal do Paraná, UFPR, CEP 80035050, Curitiba (PR), Bolsista do CNPq.
} 


\section{INTRODUÇÃO}

A cultura da erva-mate (Ilex paraguariensis Saint Hilaire) representa importância econômica, social e ecológica em toda a região sul do Brasil (PASSINATO et al., 2003). Essa espécie pode ser utilizada para a produção de bebidas (chimarrão, tereré, refrigerantes e chás), possuindo grande potencial para muitas aplicações industriais como: corante, conservante de alimentos, produtos de higiene e cosméticos (MACCARI e MAZUCHOWSKI, 2000). Sob o aspecto sócio-econômico, o plantio de erva-mate promove a fixação do homem na zona rural, pois além de ser uma cultura permanente, a sua safra ocorre justamente na entressafra dos produtos agrícolas (feijão, soja, etc.), gerando trabalho e receita (LOURENÇO et al., 1997).

$\mathrm{Na}$ silvicultura brasileira, a qualidade da muda usada nos plantios comerciais influencia o sucesso de qualquer programa de desenvolvimento florestal, e para algumas espécies já existem conhecimentos científicos e experiências suficientes na implementação do processo produtivo (XAVIER et al., 2003). Entretanto, informações técnicas sobre a produção de mudas de erva-mate via miniestaquia são escassas, o que limita o avanço de sua silvicultura.

LOURENÇO et al. (2000) salientam que o desenvolvimento da muda depende das propriedades físicas, químicas e biológicas do substrato que a sustenta, o que interfere diretamente na qualidade das mudas. CARRIJO et al. (2002) recomendam que um substrato ideal deve possuir, dentre outras características, porosidade acima de $85 \%$, capacidade de aeração entre 10 e $30 \%$ e água facilmente assimilável de 20 a $30 \%$. Dentre os atributos químicos, a faixa de $\mathrm{pH}$ considerada ideal para os cultivos varia de acordo com o substrato, ambiente e cultura (SODRÉ et al., 2005). No entanto, a escolha do material a ser utilizado depende não só do objetivo a ser alcançado, mas também da disponibilidade do local, do custo de aquisição e da experiência do viveirista (SALVADOR et al., 2001, CORREIA et al., 2005).

Como não é fácil encontrar materiais puros com as características ideais para um bom substrato, devem ser misturados vários materiais ou produtos, com o objetivo de melhorar suas propriedades físicas e químicas (SANTOS et al., 2000). Nesse sentido, SCHMITZ et al. (2002) ao testarem as propriedades químicas e físicas de substratos para o cultivo de mudas em recipientes, observaram que a adição de casca de arroz carbonizada à turfa, induziu redução do excesso de água, amenizando os problemas com excesso de umidade apresentados por esse material orgânico.

GUERRINI e TRIGUEIRO (2004) ao estudar os atributos físicos e químicos de substratos compostos por biossólidos e casca de arroz carbonizada verificaram que foram considerados mais adequados, para o desenvolvimento de mudas de espécies florestais, os substratos com 40 a $70 \%$ de casca de arroz carbonizada no seu volume total.
CARRIJO et al. (2002) destacam as boas propriedades físicas da fibra de coco, a não reação com os nutrientes da adubação, longa durabilidade sem alterações das características físicas, possibilidade de esterilização, abundância da matéria prima, que é renovável, e o baixo custo. Essas características de certa forma podem potencializar o uso da fibra de coco como substrato na propagação vegetativa de espécies florestais, sendo importante a realização de estudos que abordem esse assunto.

WENDLING (2004) ressalta a necessidade de pesquisas com substratos que visem a melhoria do enraizamento de propágulos de erva-mate, destacando a vermiculita, serragem, casca de arroz carbonizada, casca de Pinus semi-decomposta e diversas misturas desses constituintes. $O$ autor salienta que as condições de manejo devem ser testadas, uma vez que os substratos apresentam diferentes capacidades de retenção de água e, consequentemente, potencialidades variáveis de proporcionar o enraizamento de estacas.

Quanto ao enraizamento de miniestacas de erva-mate, WENDLING e SOUZA JUNIOR (2003) ao trabalhar com material juvenil obtiveram média geral de $75 \%$ de sobrevivência das mudas com a utilização de substrato a base de casa de arroz carbonizada, vermiculita de granulometria fina e substrato comercial para enraizamento a base de casca de Pinus e vermiculita $(3,5: 3,5: 3 \mathrm{v} / \mathrm{v})$. Em outro estudo, WENDLING et al. (2007) obtiveram sobrevivência média de $85,8 \%$ de miniestacas de erva-mate cultivadas em substrato composto de vermiculita média, casca de arroz carbonizada e casca de Pinus $(1: 1: 1 \mathrm{v} / \mathrm{v})$, demonstrando influência positiva do uso da casca de arroz carbonizada e casca de Pinus como componentes do substrato na miniestaquia da ervamate.

Em relação ao ambiente inicial de cultivo, casas de vegetação equipadas com sistema de nebulização intermitente são ideais para o enraizamento de estacas com folhas (HIGA, 1983). A nebulização mantém a umidade das folhas, diminuindo a pressão de vapor das mesmas, reduzindo a temperatura e a taxa de respiração, mantendo-as funcionais por maior tempo, o que pode ser decisivo no enraizamento de muitas espécies (HARTMANN et al., 2002). Não há registros de trabalhos que relacionem o enraizamento de miniestacas de erva-mate submetidas a diferentes condições ambientais.

Nesse sentido, o presente trabalho teve como objetivo avaliar o efeito do ambiente inicial de enraizamento e diferentes composições de substratos na sobrevivência, enraizamento e vigor aéreo e radicial de miniestacas juvenis de erva-mate.

\section{METODOLOGIA}

O experimento foi instalado em fevereiro de 2005 no Laboratório de Propagação de Plantas da Embrapa Florestas, Colombo - PR. Para a obtenção das minicepas, inicialmente as sementes foram 
estratificadas em areia média durante quatro meses e, posteriormente semeadas em tubetes plásticos de $110 \mathrm{~cm}^{3}$, com substrato a base de casca de Pinus e vermiculita $(1: 1 \mathrm{v} / \mathrm{v})$. Após seis meses, as mudas com altura em torno de $15 \mathrm{~cm}$, foram plantadas em "canaletão" contendo areia de granulometria média sob sistema semi-hidropônico. Visando a emissão de brotações, a primeira poda do ápice (à altura de 5 a $8 \mathrm{~cm}$ ) foi realizada 10 dias após o plantio no "canaletão", constituindo assim as minicepas.

As minicepas receberam diariamente nutrientes por gotejamento a uma vazão de $5 \mathrm{~L} \mathrm{~m}^{-2}$, sendo a solução nutritiva composta por monoamônio fosfato $\left(0,04 \mathrm{~g} \mathrm{~L}^{-1}\right)$, sulfato de magnésio $\left(0,40 \mathrm{~g} \mathrm{~L}^{-1}\right)$, nitrato de potássio $\left(0,44 \mathrm{~g} \mathrm{~L}^{-1}\right)$, sulfato de amônio $\left(0,31 \mathrm{~g} \mathrm{~L}^{-1}\right)$, cloreto de cálcio $\left(0,79 \mathrm{~g} \mathrm{~L}^{-1}\right)$, ácido bórico $\left(2,88 \mathrm{mg} \mathrm{L}^{-1}\right)$, sulfato de manganês $\left(3,70 \mathrm{mg} \mathrm{L}^{-1}\right)$, molibdato de sódio $\left(0,18 \mathrm{mg} \mathrm{L}^{-1}\right)$, sulfato de zinco $\left(0,74 \mathrm{mg} \mathrm{L}^{-1}\right)$ e hidroferro em pó $\left(81,80 \mathrm{mg} \mathrm{L}^{-1}\right)$.

Decorridos 130 dias da poda do ápice, miniestacas foram coletadas e preparadas com comprimento médio de $5 \mathrm{~cm}$, retirando-se o ápice e deixando um par de folhas com aproximadamente 1/ 3 de sua área foliar inicial. Não foi realizado tratamento asséptico, bem como tratamento com regulador vegetal, em vista de se tratar de material juvenil.

Em seguida, foram plantadas em tubetes de $110 \mathrm{~cm}^{3}$, onde se efetuou a inserção de aproximadamente $2 \mathrm{~cm}$ da miniestaca nos seguintes substratos de cultivo: S1 - substrato para enraizamento a base de casca de Pinus, S2 substrato para enraizamento a base de casca de Pinus e vermiculita, S3 - casca de arroz carbonizada + vermiculita fina + substrato para enraizamento a base de casca de Pinus e vermiculita (1:1:1 v/v), S4 - casca de arroz carbonizada + substrato para enraizamento a base de casca de Pinus e vermiculita $(1: 1 \mathrm{v} / \mathrm{v})$, S5 - casca de arroz carbonizada + vermiculita fina $(1: 1 \mathrm{v} / \mathrm{v})$ e S6 - fibra de coco.

Posteriormente, as bandejas contendo os tubetes com as miniestacas foram transferidas para dois ambientes de enraizamento, os quais diferiram principalmente quanto a sua automatização: casa de vegetação automatizada (CVA) e casa de vegetação simples (CVS). A CVA possuía controle da temperatura ( $\mathrm{T}$ menor ou igual a $30{ }^{\circ} \mathrm{C}$ ) e da umidade relativa do ar (UR $>80 \%$, mantidos por meio de nebulização), sendo ambas as variáveis controladas automaticamente por termostato, umidostato e timer. Quanto a CVS, somente a irrigação foi controlada, sendo compreendida de microaspersões de 10 segundos em intervalos de 10 minutos, diariamente das 8 às 18 horas. Os dados da temperatura do ar máxima, mínima e média ocorridos durante a permanência das miniestacas em ambos os ambientes de enraizamento (fevereiro a abril de 2005) foram monitorados diariamente e estão apresentados na Tabela 1.

TABELA 1 - Temperaturas do ar máxima, média e mínima de fevereiro a abril de 2005 em casa de vegetação automatizada (CVA) e casa de vegetação simples (CVS) para o enraizamento de miniestacas de erva-mate (Fonte: Laboratório de Propagação de Plantas - Embrapa Florestas).

\begin{tabular}{|c|c|c|c|c|c|c|c|c|c|}
\hline \multirow{4}{*}{$\begin{array}{l}\text { Ambiente de } \\
\text { Enraizamento }\end{array}$} & \multicolumn{9}{|c|}{ Meses de 2005} \\
\hline & \multicolumn{3}{|c|}{ Fevereiro } & \multicolumn{3}{|c|}{ Março } & \multicolumn{3}{|c|}{ Abril } \\
\hline & Tmáx. & Tméd. & Tmín. & Tmáx. & Tméd. & Tmín. & Tmáx. & Tméd. & Tmín. \\
\hline & \multicolumn{3}{|c|}{--1-- } & \multicolumn{3}{|c|}{--1 } & \multicolumn{3}{|c|}{--1-- } \\
\hline CVA & $29,9 \pm 1,07$ & $23,2 \pm 1,06$ & $16,5 \pm 1,47$ & $30,1 \pm 0,35$ & $23,4 \pm 0,81$ & $16,7 \pm 1,30$ & $30,1 \pm 2,56$ & $23,4 \pm 1,79$ & $16,7 \pm 1,38$ \\
\hline CVS & $31,3 \pm 2,86$ & $26,5 \pm 1,71$ & $21,6 \pm 0,98$ & $34,0 \pm 4,07$ & $26,5 \pm 2,18$ & $19,0 \pm 1,22$ & $29,7 \pm 3,78$ & $23,5 \pm 2,83$ & $17,2 \pm 2,10$ \\
\hline
\end{tabular}

Onde: Tmáx = temperatura máxima, Tméd = temperatura média, Tmín = temperatura mínima, $\sigma$ = desvio padrão em relação ao valor médio.

As miniestacas permaneceram nos dois ambientes durante 60 dias para o enraizamento, sendo em seguida transferidas para casa de sombra com sombrite de $50 \%$ para aclimatação, durante 30 dias e, posteriormente, para área de pleno sol por mais 30 dias, visando a rustificação e crescimento. A partir da fase de aclimatação até a fase de rustificação, realizaram-se adubações semanais de cobertura com $6 \mathrm{ml}$ por muda da seguinte formulação: sulfato de amônio (4 $\left.\mathrm{g} \mathrm{L}^{-1}\right)$, superfosfato triplo (10 g $\left.\mathrm{L}^{-1}\right)$, cloreto de potássio (4 $\left.\mathrm{g} \mathrm{L}^{-1}\right)$, e solução de micronutrientes $\left(10 \mathrm{ml} \mathrm{L}^{-1}\right)$, composta por: $9 \%$ de $\mathrm{Zn}$; $1,8 \%$ de $\mathrm{B} ; 0,8 \%$ de $\mathrm{Cu} ; 3 \%$ de $\mathrm{Fe} ; 2 \%$ de $\mathrm{Mn}$ e $0,12 \%$ de Mo.
Ao longo do experimento avaliaram-se a sobrevivência das miniestacas na saída da casa de enraizamento, saída da casa de sombra e enraizamento em área de pleno sol, sendo consideradas vivas as miniestacas que se apresentavam verdes. Já na avaliação da sobrevivência na área de pleno sol, aos 120 dias após a miniestaquia, consideraram-se somente as miniestacas com raízes formadas, das quais foi avaliado o comprimento total das brotações, número de folhas e o comprimento total do sistema radicial, segundo metodologia descrita por TENNANT (1975).

O experimento foi conduzido em delineamento blocos ao acaso no arranjo bifatorial $(6 \times 2)$, sendo seis formulações de substratos 
dispostos em dois ambientes com cinco blocos e oito miniestacas por parcela. Os dados foram submetidos à análise de variância, tendo as médias sido discriminadas pelo teste de agrupamento de Scott-Knott a $5 \%$ de probabilidade.

\section{RESULTADOS E DISCUSSÃO}

Não houve interação entre os ambientes de enraizamento e substratos para as variáveis na saída da casa de enraizamento (SCE), saída da casa de sombra (SCS) e enraizamento em área de pleno sol (APS) (Tabela 2), entretanto existiu interação para as variáveis comprimento total das brotações (CTB), número de folhas (NF) e o comprimento total do sistema radicial (CTSR ).

TABELA 2 - Resumo da análise da variância para sobrevivência das miniestacas na saída da casa de enraizamento (SCE), na saída da casa de sombra (SCS), enraizamento na área de pleno sol (APS), comprimento total das brotações (CTB), do número de folhas (NF) e comprimento total do sistema radicial (CTSR) de miniestacas de erva-mate em função dos substratos testados: S1 substrato para enraizamento a base de casca de Pinus, S2 - substrato para enraizamento a base de casca de Pinus e vermiculita, S3 - casca de arroz carbonizada + vermiculita fina + substrato para enraizamento a base de casca de Pinus e vermiculita (1:1:1 v/v), S4 - casca de arroz carbonizada + substrato para enraizamento a base de casca de Pinus e vermiculita (1:1 v/v), S5 - casca de arroz carbonizada + vermiculita fina $(1: 1 \mathrm{v} / \mathrm{v})$ e S6 - fibra de coco e, dos ambientes de enraizamento: casa de vegetação automatizada e casa de vegetação simples.

\begin{tabular}{|c|c|c|c|c|c|c|c|}
\hline \multirow[b]{2}{*}{$\begin{array}{l}\text { Causas da } \\
\text { Variação }\end{array}$} & \multirow[b]{2}{*}{$\mathrm{GL}$} & \multicolumn{6}{|c|}{ Quadrados Médios } \\
\hline & & $\begin{array}{l}\text { SCE } \\
(\%)\end{array}$ & $\begin{array}{l}\operatorname{SCS}^{(1)} \\
(\%)\end{array}$ & $\begin{array}{l}\text { APS } \\
(\%)\end{array}$ & $\begin{array}{l}\text { CTB } \\
(\mathrm{cm})\end{array}$ & NF & $\begin{array}{c}\text { CTSR }^{(2)} \\
(\mathrm{cm})\end{array}$ \\
\hline Bloco & 4 & $1026,04^{\text {ns }}$ & $0,3697^{\text {ns }}$ & $1026,04^{\text {ns }}$ & $0,34^{\text {ns }}$ & $3,49^{\text {ns }}$ & $1,552^{\mathrm{ns}}$ \\
\hline Ambiente (Amb) & 1 & $3375,00^{*}$ & $0,7238^{*}$ & $9690,10^{*}$ & $8,02^{*}$ & $112,37^{*}$ & $4,335^{*}$ \\
\hline Substrato (Sub) & 5 & $12833,33^{*}$ & $3,2176^{\star}$ & $9544,27^{*}$ & $15,84^{*}$ & $61,90^{*}$ & $62,699^{*}$ \\
\hline Amb * Sub & 5 & $1625,00^{\text {ns }}$ & $0,5854^{\mathrm{ns}}$ & $3044,27^{\text {ns }}$ & $2,08^{* *}$ & $27,34^{*}$ & $8,419^{*}$ \\
\hline Resíduo & 44 & 9223,96 & 2,1289 & 15286,45 & 33,56 & 62,30 & 14,495 \\
\hline Média & - & 78,33 & 72,50 & 60,21 & 1,07 & 5,01 & 150,72 \\
\hline CV (\%) & - & 18,48 & 19,99 & 30,96 & 37,90 & 23,76 & 15,59 \\
\hline $\begin{array}{l}\text { "ns" } F \text { não sign } \\
\text { respectivamente } \\
=\text { coeficiente de }\end{array}$ & dac & trancforms & ilidade; & $\begin{array}{l}\mathrm{e} \\
\mathrm{e} \sqrt{\frac{p}{100}} \mathrm{e}\end{array}$ & or $\sqrt{\frac{p}{10}}$ & $\begin{aligned} & 5 \% \mathrm{~d} f \\
= & \text { graus }\end{aligned}$ & $\begin{array}{l}\text { sabilidade, } \\
\text { rdade; CV }\end{array}$ \\
\hline
\end{tabular}

Os maiores comprimentos totais das brotações (CTB) na casa de vegetação automatizada (CVA), foram os obtidos com o uso dos substratos $\mathrm{S} 2(2,5 \mathrm{~cm})$ e S4 $(2,2 \mathrm{~cm})$ (Figura 1). Os menores valores foram observados com o uso dos substratos
S3 $(0,9 \mathrm{~cm}), \mathrm{S} 5(0,8 \mathrm{~cm})$ e $\mathrm{S} 6(0,9 \mathrm{~cm})$. Na casa de vegetação simples (CVS), o substrato que resultou em maior comprimento total das brotações foi o S2 $(1,6 \mathrm{~cm})$. 


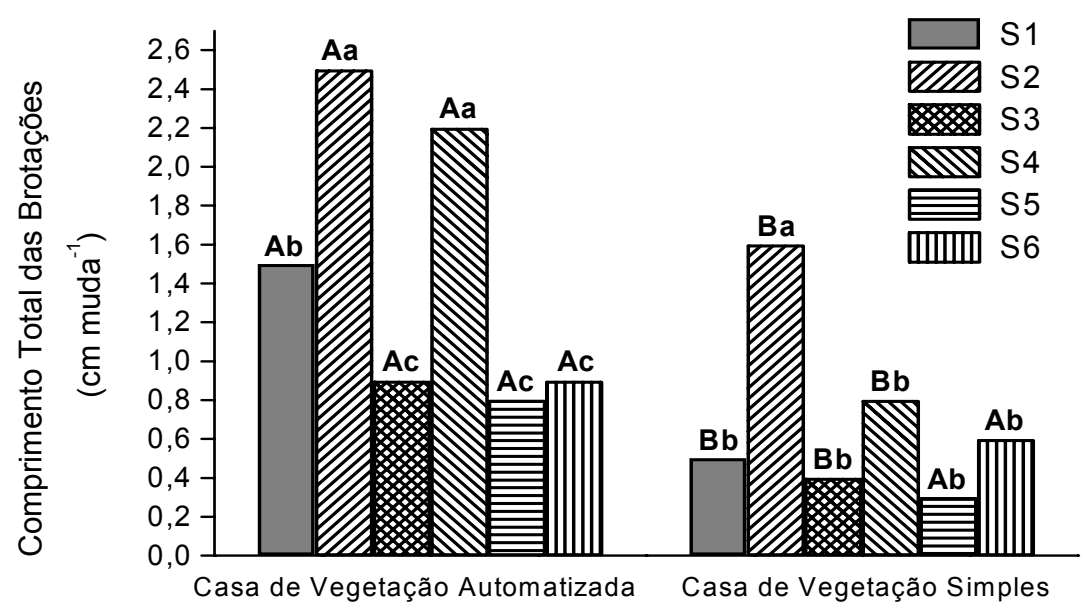

FIGURA 1 - Médias do comprimento total das brotações, aos 120 dias de cultivo, de miniestacas de erva-mate em função dos substratos testados: S1 - substrato para enraizamento a base de casca de Pinus, S2 - substrato para enraizamento a base de casca de Pinus e vermiculita, S3 - casca de arroz carbonizada + vermiculita fina + substrato para enraizamento a base de casca de Pinus e vermiculita $(1: 1: 1 \mathrm{v} / \mathrm{v}), \mathrm{S} 4$ - casca de arroz carbonizada + substrato para enraizamento a base de casca de Pinus e vermiculita (1:1 v/v), S5 - casca de arroz carbonizada + vermiculita fina (1:1 v/v) e S6 - fibra de coco e, dos ambientes de enraizamento: casa de vegetação automatizada e casa de vegetação simples. Médias seguidas de mesma letra maiúscula para o mesmo substrato entre os dois ambientes e letras minúsculas entre substratos dentro do mesmo ambiente não diferem significativamente pelo teste de agrupamento de Scott-Knott a $5 \%$ de probabilidade.

Em se tratando dos dois ambientes de enraizamento, pode-se notar superioridade da CVA em relação a CVS, exceção feita aos substratos S5 e S6. A única diferença marcante destes dois substratos em relação aos demais é a ausência de materiais orgânicos, o que pode ter resultado em menor capacidade de crescimento das brotações da parte aérea aos 120 dias, como resultado de um menor crescimento de raízes.
Comportamento semelhante foi observado em relação ao número de folhas, em que os melhores resultados foram obtidos com os substratos S1, S2 e S4 em casa de vegetação automatizada. Em se tratando da casa de vegetação simples, maiores números de folhas foram obtidos com os substratos S2, S4 e S6 (Figura 2). A maioria dos tratamentos de substratos resultaram em maior número de folhas na casa de vegetação automatizada em relação a casa de vegetação simples, exceção aos substratos S5 e S6. 


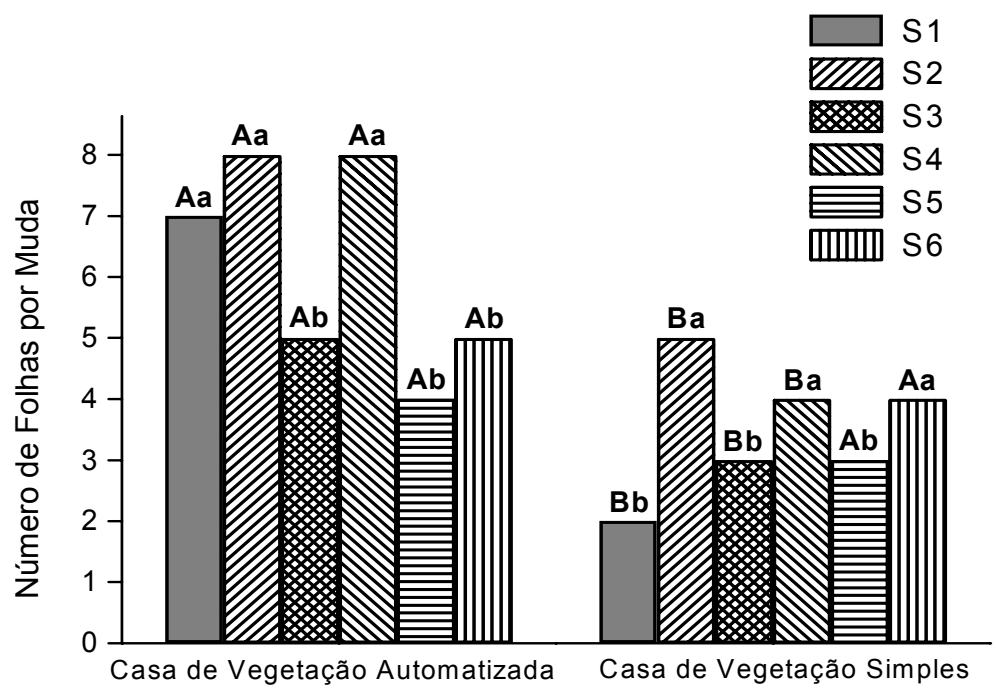

FIGURA 2 - Médias de número de folhas, aos 120 dias de cultivo, de miniestacas de erva-mate em função dos substratos testados: S1 - substrato para enraizamento a base de casca de Pinus, S2 - substrato para enraizamento a base de casca de Pinus e vermiculita, S3 - casca de arroz carbonizada + vermiculita fina + substrato para enraizamento a base de casca de Pinus e vermiculita (1:1:1 v/v), S4 - casca de arroz carbonizada + substrato para enraizamento a base de casca de Pinus e vermiculita (1:1 v/v), S5 - casca de arroz carbonizada + vermiculita fina (1:1 v/v) e S6 - fibra de coco e, dos ambientes de enraizamento: casa de vegetação automatizada e casa de vegetação simples. Médias seguidas de mesma letra maiúscula para o mesmo substrato entre os dois ambientes e letras minúsculas entre substratos dentro do mesmo ambiente não diferem significativamente pelo teste de agrupamento de Scott-Knott a $5 \%$ de probabilidade.

MIRANDA e MIRANDA (2000) ao trabalharem com enraizamento de estacas de mogno (Swietenia macrophylla King) em câmara úmida, constataram correlação significativa e positiva da retenção foliar com brotação e com número de brotos. A presença de folhas nas miniestacas é um estímulo ao enraizamento, uma vez que favorece a fotossíntese. Além disso, segundo TAIZ e ZEIGER (2004) a biossíntese de AIA está associada aos tecidos com rápida divisão celular e crescimento, especialmente nas partes aéreas, desta forma a presença de folhas pode desempenhar um papel decisivo no enraizamento das miniestacas. Isso ressalta a importância da presença de folhas nas miniestacas, o que contribui para aumentar a sobrevivência destas e a probabilidade de formação de raízes.

No entanto, a perda de água pelas mesmas pode ocasionar a morte das miniestacas antes da formação das raízes adventícias. Para espécies que enraízam com facilidade, a rápida formação das raízes compensa a quantidade de água perdida pelas folhas, mas em espécies de enraizamento lento, como no caso da erva-mate, a transpiração das folhas deve ser reduzida ao máximo (HIGA, 1983).

Todas as atividades metabólicas e fisiológicas das plantas são reguladas pelo nível de energia calorífica existente no sistema, geralmente medida por meio da temperatura (FLOSS, 2004).
Pode-se observar que a temperatura nos dois ambientes iniciais de enraizamento variou ao longo do tempo, entretanto existiu menor variação desse fator na casa de vegetação automatizada (CVA) do que na casa de vegetação simples (CVS) (Tabela 1), pois, na maioria das vezes, o valor médio da temperatura máxima superou $30,1^{\circ} \mathrm{C}$ na CVS, chegando algumas vezes acima de $33,0^{\circ} \mathrm{C}$. Essa variação não foi observada na CVA, onde os valores médios de temperatura máxima permaneceram próximos da faixa de $30,0^{\circ} \mathrm{C}$, na maioria das observações.

A variação da média das temperaturas mínimas na CVA, na maioria das vezes, ficou na faixa de 16,5 a $16,7^{\circ} \mathrm{C}$. Entretanto, na CVS, os valores foram mais elevados chegando até $21,6{ }^{\circ} \mathrm{C}$ no mês de fevereiro, ocorrendo novamente uma demasiada variação da temperatura.

A temperatura pode regular a emissão de raízes adventícias sendo importante que o seu desenvolvimento preceda o da parte aérea. Deve-se evitar temperaturas do ar demasiadamente altas, pois tendem a estimular o desenvolvimento de gemas antes das raízes, além de causar excessiva perda de água pelas folhas (HIGA, 1983). Esse fator pode levar as estacas ao dessecamento, tendo em vista que a perda de água é sempre mais rápida do que a sua absorção (ZUFFELLATO-RIBAS e RODRIGUES, 2001). Para GOMES (1987), a temperatura na base 
da estaca deve ser mais elevada do que a temperatura ambiente, pois proporciona maior atividade na sua base, reduzindo a respiração e a perda de água pela parte aérea.

Ao se analisar o aspecto visual do sistema radicial formado aos 120 dias, os substratos $\mathrm{S3}$ (casca de arroz carbonizada + vermiculita fina + substrato para enraizamento a base de casca de Pinus e vermiculita, 1:1:1 v/v) e S5 (casca de arroz

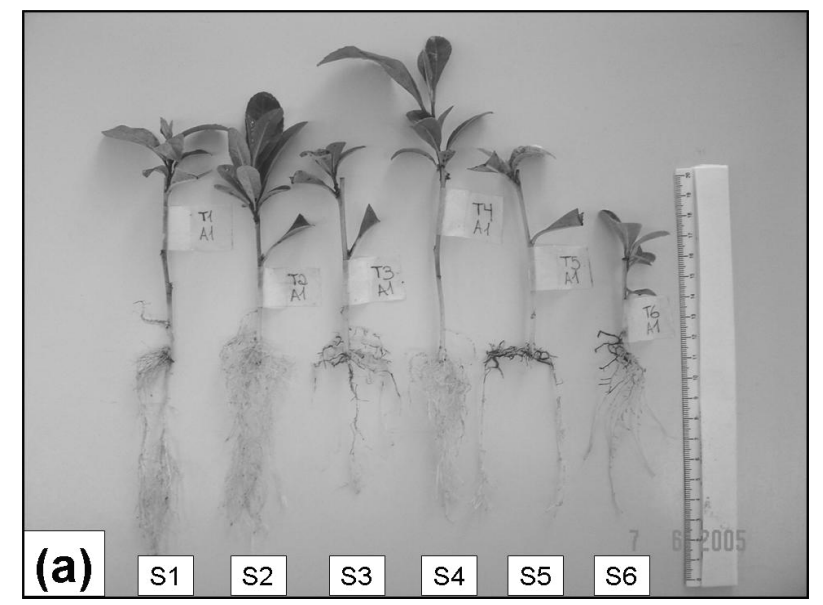

FIGURA 3 - Miniestacas enraizadas de erva-mate (Ilex paraguariensis Saint Hilaire) aos 120 dias de cultivo. (a) - casa de vegetação automatizada, (b) - casa de vegetação simples. S1 - substrato para enraizamento a base de casca de Pinus, S2 - substrato para enraizamento a base de casca de Pinus e vermiculita, S3 - casca de arroz carbonizada + vermiculita fina + substrato para enraizamento a base de casca de Pinus e vermiculita (1:1:1 v/v), S4 - casca de arroz carbonizada + substrato para enraizamento a base de casca de Pinus e vermiculita (1:1 v/v), S5 - casca de arroz carbonizada + vermiculita fina (1:1 v/v) e S6 - fibra de coco (Fonte: Laboratório de Propagação de Plantas Embrapa Florestas).

A falta de raízes impede a absorção de água suficiente, enquanto as folhas intactas e o crescimento da nova brotação continuam a perder água por transpiração (ZUFFELLATO-RIBAS e RODRIGUES, 2001).

Em ambos os ambientes de enraizamento o substrato S2 proporcionou maior comprimento total do sistema radicial, não diferindo significativamente apenas do substrato $\mathrm{S} 1$ na casa de vegetação carbonizada + vermiculita fina, $1: 1 \mathrm{v} / \mathrm{v}$ ) apresentaram algumas raízes necrosadas (Figura 3 ). Esse efeito não foi verificado nos outros tratamentos. Pode-se observar que os substratos S1, S2 e S4 que tiveram maiores proporções de casca de Pinus, apresentaram raízes mais vigorosas em relação aos substratos $S 3$, S5 e S6, independente do ambiente inicial de enraizamento.

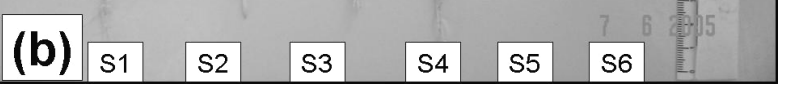


BRONDANI, G.E. et al. Ambiente de enraizamento e substratos...

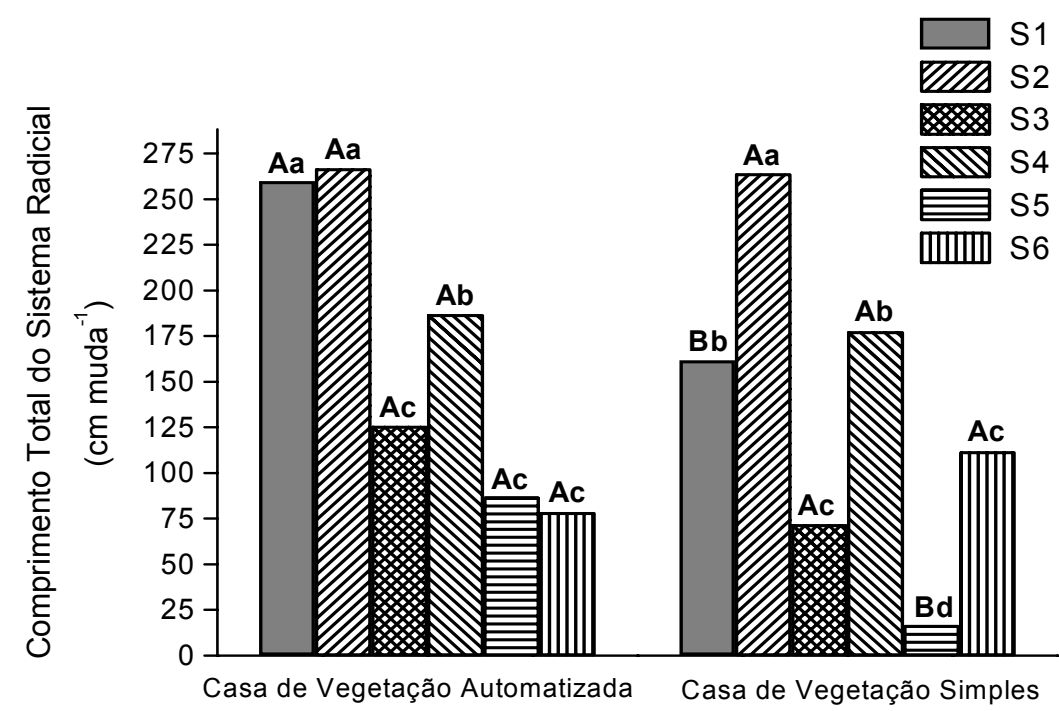

FIGURA 4 - Médias de comprimento total do sistema radicial, aos 120 dias de cultivo, de miniestacas de ervamate em função dos substratos testados: S1 - substrato para enraizamento a base de casca de Pinus, S2 - substrato para enraizamento a base de casca de Pinus e vermiculita, S3 - casca de arroz carbonizada + vermiculita fina + substrato para enraizamento a base de casca de Pinus e vermiculita $(1: 1: 1 \mathrm{v} / \mathrm{v})$, S4 - casca de arroz carbonizada + substrato para enraizamento a base de casca de Pinus e vermiculita (1:1 v/v), S5 - casca de arroz carbonizada + vermiculita fina (1:1 v/v) e S6 - fibra de coco e, dos ambientes de enraizamento: casa de vegetação automatizada e casa de vegetação simples. Médias seguidas de mesma letra maiúscula para o mesmo substrato entre os dois ambientes e letras minúsculas entre substratos dentro do mesmo ambiente não diferem significativamente pelo teste de agrupamento de Scott-Knott a $5 \%$ de probabilidade.

Com base nessas características, tanto o ambiente de enraizamento quanto o tipo de substrato adotado são de grande importância na produção de mudas de erva-mate via miniestaquia, tendo em vista que o crescimento das plantas no campo, após o seu plantio definitivo, está diretamente relacionado ao vigor radicial.

A sobrevivência das miniestacas aos 60 dias (saída da casa de vegetação-SCE) variou em função do tipo de substrato, sendo os menores valores obtidos nos substratos S2 $(55,0 \%)$ e S6 $(61,2 \%)$ (Figura 5). Aos 90 dias (saída da casa de sombraSCS) os maiores valores médios de sobrevivência das miniestacas foram encontrados no substrato S5 $(91,2 \%)$ e menores nos substratos S2 $(48,8 \%)$ e S6 (52,5\%). Já aos 120 dias (área de pleno sol-APS), os maiores resultados foram obtidos com os substratos S1 $(68,8 \%)$, S3 $(68,8 \%)$ e S4 $(77,5 \%)$ e os menores nos substratos S2 $(43,8 \%)$, S5 $(57,5 \%)$ e S6 $(45,0 \%)$. 


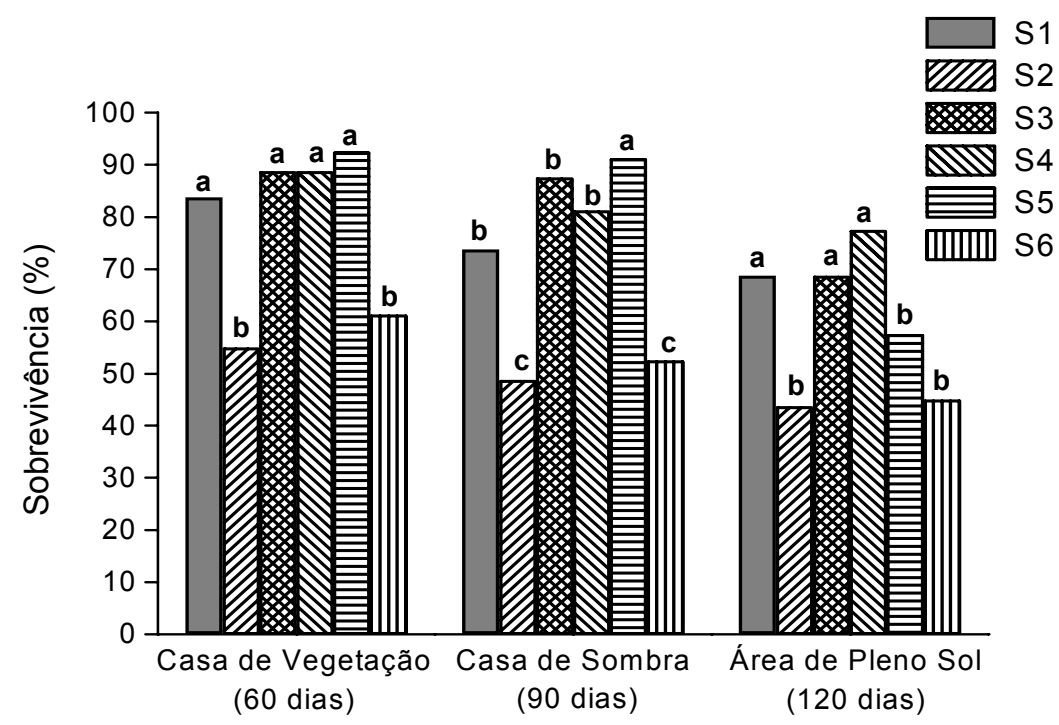

FIGURA 5 - Médias de sobrevivência de miniestacas de erva-mate na saída da casa de vegetação, saída da casa de sombra e na área de pleno sol em função dos substratos testados: S1 - substrato para enraizamento a base de casca de Pinus, S2 - substrato para enraizamento a base de casca de Pinus e vermiculita, S3 - casca de arroz carbonizada + vermiculita fina + substrato para enraizamento a base de casca de Pinus e vermiculita (1:1:1 v/v), S4 - casca de arroz carbonizada + substrato para enraizamento a base de casca de Pinus e vermiculita (1:1 v/v), S5 - casca de arroz carbonizada + vermiculita fina $(1: 1 \mathrm{v} / \mathrm{v})$ e S6 - fibra de coco. Médias seguidas de mesma letra minúscula entre os substratos dentro da mesma época não diferem significativamente pelo teste de Scott-Knott a $5 \%$ de probabilidade.

A CVA apresentou superioridade em relação a CVS quanto à sobrevivência das miniestacas de erva-mate em todas as épocas de avaliação (Figura 6). Ao serem transferidas da casa de sombra para a área de pleno sol, as miniestacas que permaneceram na CVS, apresentaram a maior mortalidade (cerca de $30 \%)$. Esse fato não foi observado para as miniestacas provenientes da CVA como ambiente inicial de cultivo, não diferindo significativamente quanto a sobrevivência. Em geral, a sobrevivência das miniestacas na APS que foram provenientes da CVA foi de $73 \%$, valores próximos aos encontrados por WENDLING e SOUZA JUNIOR (2003) e WENDLING et al. (2007) para miniestaquia de ervamate de material juvenil, enquanto que as provenientes da CVS a sobrevivência foi de $47 \%$. De acordo com este resultado, quando da utilização de um ambiente como a CVS para enraizamento de miniestacas de erva-mate, as mesmas deverão permanecer durante um maior período no ambiente inicial visando a formação de um sistema radicial suficiente para manter as mudas vivas quando da passagem para a casa de sombra e área de pleno sol. 


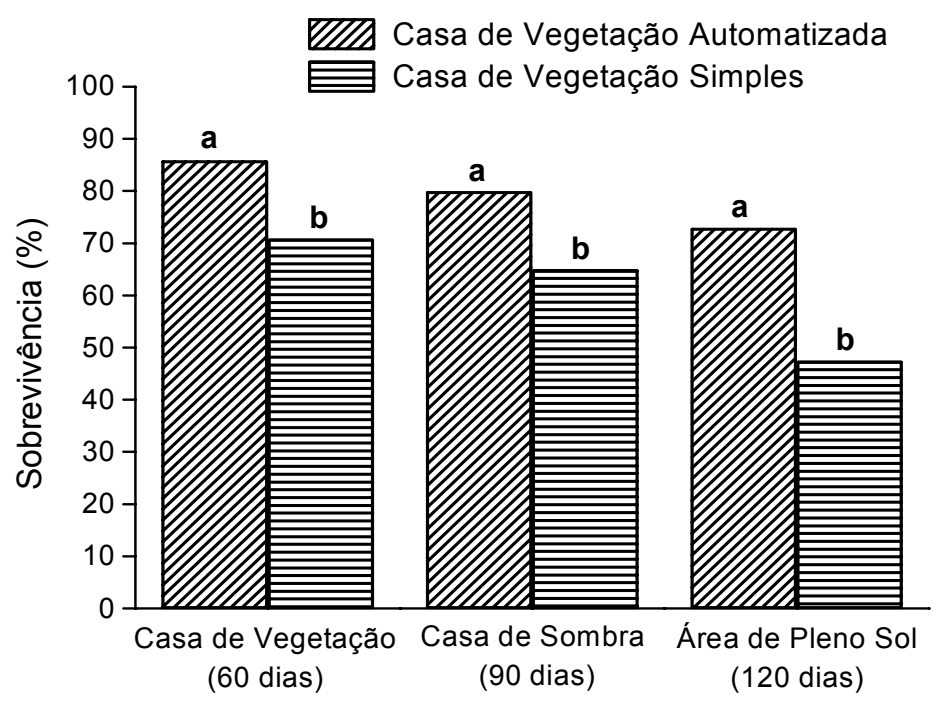

FIGURA 6 - Médias de sobrevivência de miniestacas de erva-mate na saída da casa de vegetação, saída da casa de sombra e na área de pleno sol em função dos ambientes iniciais de cultivo. Médias seguidas de mesma letra minúscula dentro da mesma época de avaliação não diferem significativamente pelo teste de Scott-Knott a $5 \%$ de probabilidade.

O substrato $\mathrm{S} 5$ esteve entre os maiores índices de sobrevivência nas avaliações aos 60 e 90 dias, entretanto aos 120 dias, observou-se uma acentuada mortalidade das miniestacas (cerca de $40 \%$ ) (Figura 5), assim como um número muito reduzido de folhas e do comprimento total do sistema radicial. Este fato pode estar relacionado a presença de somente materiais inertes neste tratamento (casca de arroz carbonizada e vermiculita). Assim sendo, caso o mesmo for utilizado para o enraizamento de miniestacas de erva-mate deverá ser suplementada nutrição adicional em cobertura ou efetuado o transplante do material enraizado para outro substrato, visando uma maior sobrevivência e crescimento aéreo e radicial das mudas formadas.

Os substratos que apresentaram a maior mortalidade na área de pleno sol foram o S2, S5 e o S6, porém os substratos $\mathrm{S} 1, \mathrm{~S} 3$ e $\mathrm{S} 4$ apresentaram a maior sobrevivência das miniestacas em cada época de avaliação.

O fato de algumas composições de substratos testadas nesse trabalho não ter apresentado resultados satisfatórios, não inviabiliza completamente sua utilização para a miniestaquia de erva-mate. No entanto, deverão ser feitos ajustes das condições de umidade e temperatura do ambiente de enraizamento e/ou a mistura de componentes que resultem em maior drenagem.

\section{CONCLUSÕES}

1) A casa de vegetação com controle de umidade e temperatura foi superior a casa de vegetação sem controle.

2) O uso do substrato casca de arroz carbonizada + substrato para enraizamento a base de casca de Pinus e vermiculita $(1: 1 \mathrm{v} / \mathrm{v})$ é aconselhado para ser usado nos dois ambientes para o enraizamento de miniestacas de erva-mate oriundas de material juvenil.

3) Caso for utilizado um ambiente como a casa de vegetação sem controle para o enraizamento de miniestacas de erva-mate, as mesmas deverão permanecer por mais tempo neste ambiente para que possam formar um sistema radicial vigoroso.

\section{AGRADECIMENTO}

À Embrapa Florestas pelo apoio concedido para a realização desse trabalho. 
BRONDANI, G.E. et al. Ambiente de enraizamento e substratos...

\section{REFERÊNCIAS}

1. CARRIJO, O.A.; LIZ, R. de S.; MAKISHIMA, N. Fibra de casca de coco verde como substrato agrícola. Horticultura Brasileira, v. 20, n. 4 , p. 533-535, 2002.

2. CORREIA, D.; RIBEIRO, E. M.; LOPES, L.S.; ROSSETTI, A.G.; MARCO, C.A. Efeito de substratos na formação de portaenxertos de Psidium guajava L. CV. Ogawa em tubetes. Revista Brasileira de Fruticultura, v. 27, n. 1, p. 88-91, 2005.

3. FLOSS, E.L. Fisiologia das plantas cultivadas: o estudo que está por trás do que se vê. Passo Fundo: UPF, 2004. 536 p.

4. GOMES, A.L. Propagação clonal: princípios e particularidades. Vila Real: Universidade de Trás-os-Montes e Alto Douro, 1987. 69 p. (Série Didáctica, Ciências Aplicadas, 1).

5. GUERRINI, I.A.; TRIGUEIRO, R.M. Atributos físicos e químicos de substratos compostos por biossólidos e casca de arroz carbonizada. Revista Brasileira de Ciência do Solo, v. 28, p. 1069-1076, 2004.

6. HARTMANN, H.T.; KESTER, D.E.; DAVIES JÚNIOR, F.T.; GENEVE, R.L. Plant propagation: principles and practices. 7. ed. New Jersey: Prentice-Hall, 2002. 880 p.

7. HIGA, R.C.V. Propagação vegetativa da erva-mate (Ilex paraguariensis St. Hil.) por estaquia. In: SEMINÁRIO SOBRE ATUALIDADES E PERSPECTIVAS FLORESTAIS: Silvicultura da erva-mate, 10., 1983, Curitiba. Anais. Curitiba: Embrapa CNPF, 1983. p. 119-123. (Documentos, 15).

8. LOURENÇO, R.S.; MEDRADO, M.J.S.; FOWLER, J.A.P.; MOSELE, S.H. Influência do substrato no desenvolvimento de mudas de erva-mate (Ilex paraguariensis St. Hill.). Perspectiva, v. 24, n. 88, p. 81-99, 2000.

9. LOURENÇO, R.S.; CURCIO, G.R.; RACHWAL, M.G.; MEDRADO, M.J.S. Avaliação de níveis de nitrogênio sobre a produção de erva-mate (Ilex paraguariensis St. Hil.) em Fernandes Pinheiro, PR, em Latossolo Vermelho escuro. Boletim de Pesquisa Florestal, v. 34, p. 75-98, 1997.

10. MACCARI JR., A.; MAZUCHOWSKI, J.Z. Produtos alternativos e desenvolvimento da tecnologia industrial na cadeia produtiva da erva-mate. Curitiba: Câmara Setorial Produtiva da Erva-Mate do Paraná, 2000. 160 p.

11. MIRANDA, E.M. de; MIRANDA, K.R. de. Propagação vegetativa de mogno (Swietenia macrophylla King) por enraizamento de estacas semilenhosas em câmara úmida. Rio Branco: Embrapa Acre, 2000. 15 p. (Circular Técnica, 32).

12. PASSINATO, R. Aspectos etnoentomológicos, socioeconômicos e ecológicos relacionados à cultura da erva-mate (Ilex paraguariensis) no município de Salto do Lontra, Paraná, Brasil. Piracicaba, 2003. 112 f. Dissertação (Mestrado em Ecologia de Agroecossistemas) - Universidade de São Paulo, Escola Superior de Agricultura Luiz de Queiroz.

13. SALVADOR, E.D.; PASQUAL, M.; SPERA, M.R.N. Efeito de diferentes substratos no crescimento de samambaia-matogrossense (Polypodium aureum L.). Ciência e Agrotecnologia, v. 25, n. 4, p. 1006-1111, 2001.

14. SANTOS, C.B.; LONGHI, S.J.; HOPPE, J.M.; MOSCOVICH, F.A. Efeito do volume de tubetes e tipos de substratos na qualidade de mudas de Cryptomeria japonica (L.F.) D. don. Ciência Florestal, v. 2, n. 10, p. 1-15, 2000.

15. SCHMITZ, J.A.K.; SOUZA, P.V.D. de; KÄMPF, A.N. Propriedades químicas e físicas de substratos de origem mineral e orgânica para o cultivo de mudas em recipientes. Ciência Rural, v. 32, n. 6, p. 937-944, 2002.

16. SODRÉ, G.A.; CORÁ, J.E.; BRANDÃO, I.C.S.F.L.; SERÔDIO, M.H. de C.F. Características químicas de substratos utilizados na produção de mudas de cacaueiros. Revista Brasileira de Fruticultura, v. 27, n. 3, p. 514-516, 2005.

17. TAIZ, L.; ZEIGER, E. Fisiologia vegetal. 3 ed. Trad. SANTARÉM, E. R.; et al. Porto Alegre: Artmed, 2004. 719 p.

18. TENNANT, D. A test of a modified line intersect method of estimating root length. The Journal of Ecology, v. 63, p. 995-1001, 1975.

19. WENDLING, I. Propagação vegetativa de erva-mate (Ilex paraguariensis Saint Hilaire): estado da arte e tendências futuras. Colombo: Embrapa Florestas, 2004. 46 p. (Documentos, 91).

20. WENDLING, I.; DUTRA, L.F.; GROSSI, F. Produção e sobrevivência de miniestacas e minicepas de erva-mate cultivadas em sistema semi-hidropônico. Pesquisa Agropecuária Brasileira, v. 42, n. 2, p. 289-292, 2007.

21. WENDLING, I.; SOUZA JUNIOR, L. Propagação vegetativa de erva-mate (Ilex paraguariensis Saint Hilaire) por miniestaquia de material juvenil. In: CONGRESSO SUL-AMERICANO DA ERVA-MATE, 3.; FEIRA DO AGRONEGÓCIO DAERVA-MATE, 1., 2003. Chapecó. Anais. Chapecó: Epagri, 2003. 8 p. 1 CD-ROM.

22. XAVIER, A.; SANTOS, G.A. dos; OLIVEIRA, M.L. de. Enraizamento de miniestaca caulinar e foliar na propagação vegetativa de cedro-rosa (Cedrela fissilis Vell.). Revista Árvore, v. 27, n. 3, p. 351-356, 2003.

23. ZUFFELLATO-RIBAS, K.C.; RODRIGUES, J.D. Estaquia: uma abordagem dos principais aspectos fisiológicos. Curitiba, 2001.39p.

Recebido em 23/04/2007

Aceito em 28/05/2007 
